\title{
Identification of the Same Factor V Gene Mutation in 47 out of 50 Thrombosis- prone Families with Inherited Resistance to Activated Protein C
}

\author{
Bengt Zöller, * Peter J. Svensson, Xuhua He, and Björn Dahlbäck \\ Departments of Clinical Chemistry and *Coagulation Disorders, University of Lund, Malmö General Hospital, S-214 01 Malmö, Sweden
}

\begin{abstract}
Resistance to activated protein C (APC) is the most prevalent inherited cause of venous thrombosis. The APC resistance phenotype is associated with a single point mutation in the factor $\mathrm{V}$ gene, changing $\mathrm{Arg}^{506}$ in the APC cleavage site to a Gln. We have investigated 50 Swedish families with inherited APC resistance for this mutation and found it to be present in 47 of them. Perfect cosegregation between a low APC ratio and the presence of mutation was seen in 40 families. In seven families, the co-segregation was not perfect as 12 out of 57 APC-resistant family members were found to lack the mutation. Moreover, in three families with $A P C$ resistance, the factor $V$ gene mutation was not found, suggesting another still unidentified cause of inherited APC resistance. Of 308 investigated families members, 146 were normal, 144 heterozygotes, and 18 homozygotes for the factor $V$ gene mutation and there were significant differences in thrombosis-free survival curves between these groups. By age $33 \mathrm{yr}, \mathbf{8 \%}$ of normals, $20 \%$ of heterozygotes, and $40 \%$ of homozygotes had had manifestation of venous thrombosis. (J. Clin. Invest. 1994. 94:2521-2524.) Key words: blood coagulation - thrombophilia $\cdot$ protein $\mathrm{C} \cdot$ protein $\mathrm{S} \cdot$ factor $\mathbf{V}$
\end{abstract}

\section{Introduction}

Blood coagulation is downregulated by the protein $\mathrm{C}$ anticoagulant system (1). Protein $C$ is activated on endothelial cells by thrombin bound to thrombomodulin. Together with its cofactor, protein S, activated protein C (APC) ${ }^{1}$ degrades the activated forms of factors VIII and V (VIIIa and Va), whereas intact factors VIII and V are poor substrates for APC.

Inherited APC resistance as a cause of thrombophilia was

Bengt Zöller and Peter J. Svensson contributed equally to this work. Address correspondence to Björn Dahlbäck, MD, PhD, Department of Clinical Chemistry, Malmö General Hospital, S-21401 Malmö, Sweden. Received for publication 15 June 1994 and in revised form 22 August 1994.

1. Abbreviation used in this paper: APC, activated protein C.

J. Clin. Invest.

(C) The American Society for Clinical Investigation, Inc. $0021-9738 / 94 / 12 / 2521 / 04 \quad \$ 2.00$

Volume 94, December 1994, 2521-2524 recently discovered in a single family (2) and is already recognized as a major cause of venous thrombosis (3-6). Intact factor $V$ was found to correct APC resistance (7) which together with close linkage between APC resistance and the factor V gene $(8,9)$, suggested the molecular defect to be located in the factor $\mathrm{V}$ gene. A single point mutation ( $\mathrm{G}$ to $\mathrm{A}$ at position 1691 ) has been found in many APC-resistant individuals (811). This mutation predicts replacement of $\mathrm{Arg}^{506}$ in the APC cleavage site of factor $\mathrm{Va}$ with a Gln, which results in APCresistant factor $\mathrm{Va}(8,12)$. The prevalence in the European population of APC resistance is between 3 and $7 \%(3,5)$.

Recently, our laboratory found intact factor $\mathrm{V}$ to function in synergy with protein $S$ as cofactor to APC in a purified factor VIIIa degradation system (13). This suggests the possibility of thrombophilia being the result of other factor $\mathrm{V}$ gene mutations causing defects in the anticoagulant function of factor $\mathrm{V}$, but as yet there are no such cases described.

We have previously described a large number of families with inherited APC resistance $(2-3,9)$. To elucidate whether the $\mathrm{Arg}^{506}$ to Gln mutation was present in all of them, or if other genetic defects may also cause or contribute to the APC resistance, 308 individuals from 50 families with inherited resistance to activated protein $\mathrm{C}$ were investigated. The APC resistance was found to be associated with the same factor $\mathrm{V}$ gene mutation in 47 of the 50 families.

\section{Methods}

Patients and controls. Thrombosis patients referred to the Department for Coagulation Disorders, Malmö General Hospital, were investigated for APC resistance, the diagnosis of APC resistance being based on APC ratio $\leqslant 2.0$ in at least two samples drawn on different occasions (3). APC resistance was judged to be inherited when APC resistance was found in two or more family members. In total, 389 individuals from 50 different families were evaluated for APC resistance. DNA samples were available from 308 family members ( 179 females and 129 males), including 33 ( 22 females and 11 males) of the 50 index cases. Table I lists the sizes of the investigated kindreds. The control group, which comprised 125 healthy volunteers, has been described previously (3).

Methods. Blood sampling and routine laboratory evaluation of coagulation parameters were performed as described (3). The APC resistance test is a modified activated partial thromboplastin time reaction, in which the anticoagulant response to APC is measured $(2,3)$. Results were expressed as APC ratios (clotting time obtained using the $\mathrm{APC} / \mathrm{CaCl}_{2}$ solution divided by clotting time obtained with $\mathrm{CaCl}_{2}$ ). Genomic DNA was prepared from EDTA blood as described (14). The region in exon 10 that encodes an APC cleavage site in factor $V$ was PCR amplified from genomic DNA using the two primers: 5'GGA ACA ACA CCA 
Table I. Sizes of Investigated Kindreds

\begin{tabular}{cc}
\hline No. of individuals* & No. of families \\
\hline $2-5$ & 25 \\
$6-10$ & 17 \\
$11-18$ & 7 \\
79 & 1
\end{tabular}

* This includes individuals that were investigated for APC resistance. Descriptive statistics for the number of investigated members per family: mean, 7.8; mode, 4; median, 5.5; and $n=389$ individuals.

TGA TCA GAG CA3', and 5'TAG CCA GGA GAC CTA ACA TGT TC3' (derived from intron sequence kindly provided by Dr. W. Kane, Duke University). The PCR conditions were: $5 \mathrm{~min}$ initial denaturation at $94^{\circ} \mathrm{C}$ followed 30 cycles of $60 \mathrm{~s}$ of denaturation at $93^{\circ} \mathrm{C}, 30 \mathrm{~s}$ of annealing at $62^{\circ} \mathrm{C}$, and $90 \mathrm{~s}$ of extension at $72^{\circ} \mathrm{C}$. The 287-bp amplified product was subjected to MnlI digestion which in a normal person produced fragments of 157,93 , and $37 \mathrm{bp}$. A G to A mutation (nucleotide position 1691) in the codon for $\mathrm{Arg}^{506}$ resulted in the loss of one cleavage site, which produced fragments of 157 and $130 \mathrm{bp}$ (pattern in a homozygous individual). Analysis of a heterozygous person yielded bands of 157, 130, 93, and $37 \mathrm{bp}$. Alternatively, previously described PCR primers were used (9).

Statistical analysis. Student's $t$ test and the Mann-Whitney U test were used to compare normal and nonnormal distributed populations, respectively. The Kolmogorov-Smirnov two-sample test was used to compare the distribution of APC ratios in patients and controls. Thrombosis-free survival curves were constructed according to the Kaplan and Meier method (15). For comparison of two curves, the log rank test, resulting in a test statistic with a chi-squared distribution and one degree of freedom, was used (16). Laboratory data were expressed as mean \pm SD. A probability below 0.05 was considered significant.

\section{Results}

Laboratory results. The $\mathrm{Arg}^{506}$ to Gln mutation in the factor V gene was found in 47 of the $50(94 \%)$ APC-resistant families. Of 308 family members, 144 were heterozygous, 18 were homozygous, and 146 lacked the mutation. Out of the 33 APC-resistant index cases that were available for genetic analysis, 24 were heterozygous, 5 homozygous, and 4 lacked the mutation. APC resistance cosegregated perfectly with the factor $\mathrm{V}$ gene mutation in 40 of the 47 families. In the remaining 7 families, 12 out of 57 APC-resistant individuals lacked the mutation. APC ratios in these 12 individuals ranged from 1.3 to 2.0. APC ratios were low in all homozygous cases, whereas there was an overlap in APC ratios between heterozygotes and normals (Fig. 1). Heterozygotes with a history of thrombosis had significantly lower APC ratios than those without thrombosis ( $1.5 \pm 0.2 \mathrm{vs}$. $1.8 \pm 0.4, P<0.001$ ), and none of the heterozygotes with APC ratio $>2.0$ had had thrombosis. Moreover, relatives without the mutation but with histories of thrombosis had significant lower APC ratios than those without thrombosis, even when protein $\mathrm{S}$-deficient cases were excluded from the analysis (mean \pm SD of $2.4 \pm 0.7$ vs. $2.9 \pm 0.8, P<0.05$ ). No influence on APC ratios of age or sex was observed among normal or heterozygous relatives.

The four APC-resistant probands who lacked the mutation had severe thromboembolic disease (deep venous thrombosis, pulmonary emboli, and/or superior sagital sinus thrombosis) but no other known defect. Three of them had only slightly low

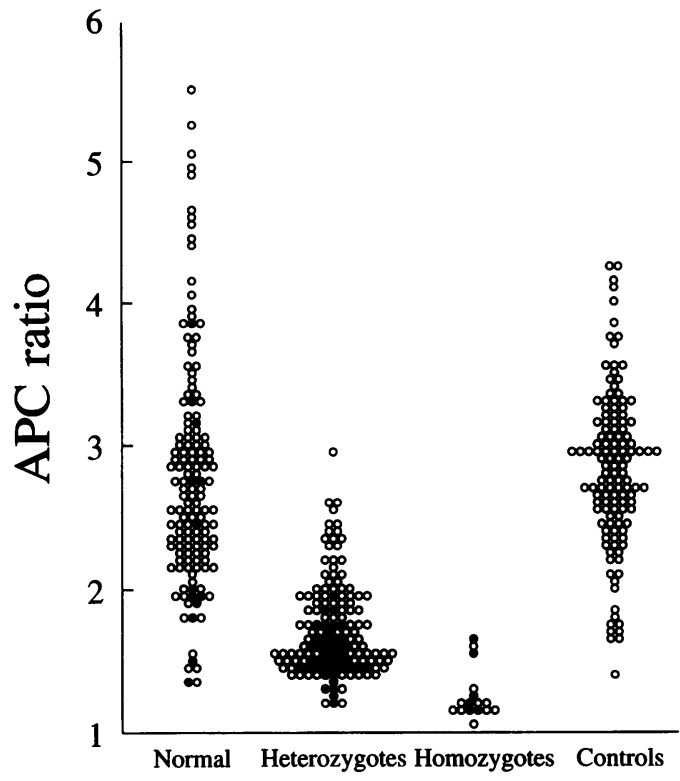

Figure 1. APC ratios in nonanticoagulated family members and in unrelated control subjects. Filled circles denote patients with a history of thrombosis. Plasmas were missing from two family members; five patients were excluded because of anticoagulant therapy. Differences in APC ratios (No., mean \pm SD) between normals $(n=143,2.8 \pm 0.8$ ), heterozygotes $(n=142,1.7 \pm 0.3)$ and homozygotes $(n=16,1.3 \pm 0.2)$ were highly significant $(P<0.001)$. Even though the mean value of controls ( $n=126,2.8 \pm 0.6$ ) was not different from that of normal relatives, the distribution of values in the two groups appeared different. However, in a Kalmogorov-Smirnov two-sample test this difference was not significant, $P=0.1$.

APC ratios (1.8-2.0), whereas the fourth had an APC ratio of 1.5. DNA samples were available for analysis from several relatives in three of the four families. In one family (five relatives tested), four APC-resistant relatives were found to be heterozygotes for the mutation, even though the index case lacked the mutation. In the remaining two families, slightly low APC ratios (1.8-2.0) were found in several relatives who were negative for the factor $\mathrm{V}$ gene mutation; three of eight relatives in one family and one of five in the other.

Independent inheritance of protein $S$ deficiency was found in three of the families. 5 protein $\mathrm{S}$-deficient individuals were heterozygous for the factor $\mathrm{V}$ mutation, 1 was homozygous and 12 were normal. 3 of the 5 heterozygotes, the homozygous case and three of those without the factor $\mathrm{V}$ gene mutation had experienced one or more thrombotic event. The homozygous case with protein $\mathrm{S}$ deficiency had severe thrombosis at the age of $10 \mathrm{yr}$. No deficiencies of protein C, antithrombin III, or plasminogen were found.

Clinical data. 43 of $144(30 \%)$ heterozygotes, 8 of 18 (44\%) homozygotes, and 14 of $146(10 \%)$ individuals without the mutation had experienced one or more venous thrombotic events (Table II). Significant differences in thrombosis-free survival of heterozygotes, homozygotes, and normals were found (Fig. 2). At $33 \mathrm{yr}$ of age, $8 \%$ of those not carrying the mutation, $20 \%$ of heterozygotes, and $40 \%$ of homozygotes had had at least one manifestation of venous thromboembolic disease. It is noteworthy that also in the group of family members who lacked the mutation, a significant difference in thrombosisfree survival between those with and those without APC resis- 


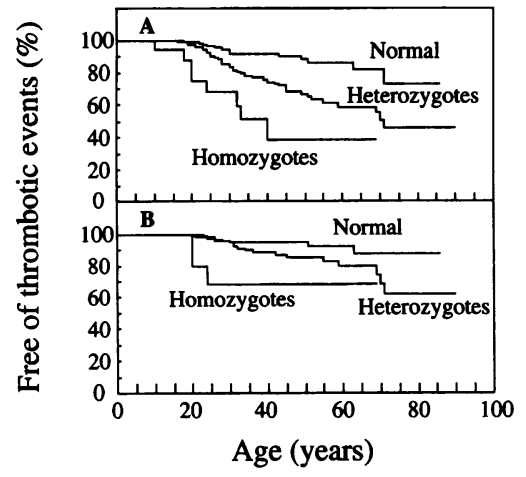

highly significant, $P<0.001$ and $P=0.01$, respectively. $(B)$ the same analysis after exclusion of the 33 APC-resistant probands and 18 protein $\mathrm{S}$-deficient family members. Differences normals vs. heterozygotes and heterozygotes vs. homozygotes were both significant, $P<0.05$.

tance was observed, even after exclusion of the four APCresistant probands (not shown).

The mean age at the first thrombotic event was $36 \mathrm{yr}$ (range 16-71) for normals, $36 \mathrm{yr}$ (range 18-71) for heterozygotes, and 25 yr (range 10-40) for homozygotes. The first thrombotic episodes were associated with circumstantial risk factors in 8 of 14 normals, in 25 of 43 heterozygotes, and in 7 out of 8 homozygotes. The most common risk factors were pregnancy, surgery, trauma, and oral contraceptives (Table III). Heterozygous women tended to have their first thrombosis at an earlier age than heterozygous men ( $34 \pm 14$ vs. $38 \pm 15)$, although the difference was not statistically significant. 29 of the $85(34 \%)$ heterozygous women and 14 of the $59(24 \%)$ heterozygous men had had thrombosis, but there was no significant difference

Table II. Clinical Manifestations in Symptomatic Family Members

\begin{tabular}{|c|c|c|c|}
\hline & Normals & Heterozygotes & Homozygotes \\
\hline Total no. of patients & 14 & 43 & 8 \\
\hline \multicolumn{4}{|l|}{$\begin{array}{l}\text { Total no. of patients } \\
\text { with indicated } \\
\text { thrombotic } \\
\text { symptom* }\end{array}$} \\
\hline DVT & $8^{8}$ & $36^{\ddagger}$ & 8 \\
\hline PE & 3 & 8 & 4 \\
\hline STP & 5 & 8 & 1 \\
\hline Recurrence & 7 & 17 & 4 \\
\hline \multicolumn{4}{|l|}{$\begin{array}{l}\text { First episode in affected } \\
\text { family members }\end{array}$} \\
\hline DVT & 7 & 31 & 6 \\
\hline PE & 3 & 1 & 0 \\
\hline STP & 4 & 7 & 0 \\
\hline Combined DVT + PE & 0 & 4 & 1 \\
\hline \multicolumn{4}{|l|}{ Combined DVT + PE } \\
\hline+ STP & 0 & 0 & 1 \\
\hline
\end{tabular}

* Since a patient may have suffered from several different thrombotic events, the numbers do not add up to the total no. of patients. DVT, deep venous thrombosis; PE, pulmonary embolism; and STP, superficial thrombophlebitis. ${ }^{\ddagger}$ One heterozygote had central retinal venous thrombosis. ${ }^{8}$ One patient had a superior sagital sinus thrombosis.
Table III. Risk Factors Associated with the First Thrombotic Episode*

\begin{tabular}{lccc}
\hline & Normals & Heterozygotes & Homozygotes \\
\hline & $n$ & $n$ & $n$ \\
Pregnancy or postpartum & 2 & 12 & 1 \\
Oral contraceptives & 2 & 8 & 3 \\
Trauma and surgery & 4 & 8 & 2 \\
Immobilization & 2 & 1 & -1 \\
Other risk factors & 1 & 1 & 1 \\
Protein S deficiency & 3 & 3 & \\
Total no. of patients & & & 7 \\
$\quad$ with risk factor & 8 & 25 & \\
\hline
\end{tabular}

* Some patients were exposed for several risk factors. ${ }^{\ddagger}$ Malignancy, varicose, and edema.

in thrombosis-free survival curves between men and women (not shown). Six heterozygotes (at age 51-74), one homozygote (at age 34) and two without the mutation (at age 55 and 64) had had an arterial thrombotic event. We have previously reported a case with severe APC resistance and arterial thrombosis (17) and more data are needed to determine whether APC resistance is associated with an increased risk of arterial thrombosis.

\section{Discussion}

The $\mathrm{Arg}^{506}$ to Gln mutation in the factor $\mathrm{V}$ gene was found in more than $90 \%$ of families with APC resistance and there were significant differences in thrombosis-free survival, as well as in APC ratios, between individuals with and without the mutation, homozygotes being more severely affected than heterozygotes. This demonstrated the factor $\mathrm{V}$ mutation to be a risk factor for thrombosis and to be the major cause of APC resistance. In a limited number of individuals with inherited APC resistance, the factor $\mathrm{V}$ gene mutation was not found, suggesting that other as yet unknown genetic defects may also cause APC resistance. Such defects appeared to be present also in some families harboring the factor $\mathrm{V}$ gene mutation, as the mutation was not found in all APC-resistant family members. The very low APC ratios observed in some heterozygous individuals may be the result of a combination of the putative second genetic defect and the factor $\mathrm{V}$ gene mutation. The presence of additional genetic defects associated with slightly low APC response was also suggested by the large group of normal relatives having APC ratios just above the lower normal limit (Fig. 1). This pattern was not observed in the controls and was not explained by age or sex differences. In this context it is also noteworthy that heterozygous family members with a history of thrombosis had lower APC ratios than those without thrombosis. Even though this is also in line with the hypothesis that these thrombosis-prone families are affected by more than one genetic defect, the possibility of lower APC ratios in thrombotic individuals being a postthrombotic phenomenon cannot be ruled out.

The APC resistance test is not a quantitative assay, but is to be regarded as a screening test. Complicated pro- and anticoagulant forces determine the APC ratio and it is easily envisioned that a number of factors may affect the results. Al- 
though sample handling, choice of reagents, and instrumentation influence the APC ratio, experience from different laboratories suggest that reliable results are obtained if the assay is performed under strictly standardized conditions $(3,5,8,18)$. If diagnosis of the factor $\mathrm{V}$ mutation in the investigated families were to be based on an APC ratio $\leq 2.0$ only, $15 \%$ of heterozygotes would not be identified (sensitivity $85 \%$ ) and $13 \%$ of normals would be classified as factor V mutants (specificity $87 \%$ ). Thus, in families with APC resistance (assuming a 50\% prevalence of the factor $\mathrm{V}$ gene mutation) the predictive value for the factor $\mathrm{V}$ mutation of a positive APC resistance test is $87 \%$, whereas the predictive value of a negative test is $85 \%$. As DNA samples were not available from the control group we do not know whether the nine individuals with APC ratio $\leq 2.0$ carry the mutation. In a recent report of a similar reference population, the mutation was found in the $3 \%$ of control individuals that had distinct APC resistance, whereas cases with borderline APC ratios were negative for the mutation $(8,18)$.

In a majority of both heterozygous and homozygous cases, thrombosis was associated with circumstantial risk factors, the most frequent being pregnancy, the use of oral contraceptives, trauma, and surgery, suggesting a combination of circumstantial and genetic risk factors to determine the risk for thrombosis. Heterozygosity for the factor $\mathrm{V}$ gene mutation is associated with a 5-10-fold increased risk of thrombosis $(8,18)$ and unless heterozygous individuals are exposed for circumstantial risk factors, thrombosis may not present until advanced age or not at all. Even though homozygosity is associated with a 50-100fold increased risk of thrombosis, affected individuals may live healthy lives without thrombosis; the oldest homozygous person in this study being free of thrombosis was $68 \mathrm{yr}$ of age. The relatively mild thrombotic tendency even in homozygous cases is in marked contrast to the severe thrombotic disease that affect individuals with homozygous protein $\mathrm{C}$ or protein $\mathrm{S}$ deficiency already in the neonatal period (19). In factor $\mathrm{Va}$, several peptide bonds are cleaved by APC and even though the $\mathrm{Arg}^{506}$ to Gln mutation is associated with APC-resistant factor Va, the resistance may not be complete. Moreover, the ability of APC to downregulate the rate of activation of coagulation at the level of factor VIIIa is unaffected by the factor V gene mutation.

In conclusion, the APC resistance phenotype is in the majority of cases associated with the same mutation in the factor $\mathrm{V}$ gene. Carriers have increased thrombotic risk compared to their normal relatives and homozygotes are the worst affected. In a minority of patients, APC resistance is due to an as yet unknown genetic defect.

\section{Acknowledgments}

The expert technical assistance of Ms. Elsy Sjörin and Mrs. Ing-Marie Persson is gratefully acknowledged. We are grateful to Dr. William
Kane at Duke University for providing the factor $\mathrm{V}$ gene intron sequence before publication.

This work was supported by the Swedish Medical Council (grants 07143 and 10827) and by grants from the Österlund Trust, the King Gustaf V 80th Birthday Trust, the King Gustaf V and Queen Victoria Trust, the Magnus Bergwall Trust, the Albert Påhlsson Trust, the Johan and Greta Kock Trust, and research funds from Malmö General Hospital.

\section{References}

1. Dahlbäck, B., and J. Stenflo. 1994. The protein C anticoagulant system. In The Molecular Basis of Blood Diseases. G. Stamatoyannopoulos, A. W. Nienhuis, and H. Varmus, editors. W. B. Saunders, Philadelphia. 599-628.

2. Dahlbäck, B., M. Carlsson, and P. J. Svensson. 1993. Familial thrombophilia due to a previously unrecognized mechanism characterized by poor anticoagulant response to activated protein C. Proc. Natl. Acad. Sci. USA. 90:1004-1008.

3. Svensson, P. J., and B. Dahlbäck. 1994. Resistance to activated protein C as a basis for venous thrombosis. N. Engl. J. Med. 330:517-522.

4. Griffin, J. H., B. Evatt, C. Wideman, and J. A. Fernánde. 1993. Anticoagulant protein C. pathway defective in majority of thrombophilic patients. Blood. 82:1989-1993.

5. Koster, T., T. R. Rosendaal, H. de Ronde, E. Briët, J. P. Vandenbroucke, and R. M. Bertina. 1993. Venous thrombosis due to poor anticoagulant response to activated protein C: Leiden thrombophilia study. Lancet. 342:1503-1506.

6. Faioni, E. M., F. Franchi, D. Asti, E. Sacchi, F. Bernardi, and P. M. Mannucci. 1993. Resistance to activated protein C in nine thrombophilic families: interference in a protein S functional assay. Thromb. Haemostasis. 70:1067-1071.

7. Dahlbäck, B., and B. Hildebrand. 1994. Inherited resistance to activated protein $\mathrm{C}$ is corrected by anticoagulant cofactor activity found to be a property of factor V. Proc. Natl. Acad. Sci. USA. 91:1396-1400.

8. Bertina, R. M., B. P. C. Koeleman, T. Koster, F. R. Rosendaal, R. J. Dirven, H. de Ronde, P. A. van der Velden, and P. H. Reitsma. 1994. Mutation in blood coagulation factor $\mathrm{V}$ associated with resistance to activated protein $\mathrm{C}$. Nature (Lond.). 369:64-67.

9. Zöller, B., and B. Dahlbäck. 1994. Linkage between inherited resistance to activated protein $\mathrm{C}$ and factor $\mathrm{V}$ gene mutation in venous thrombosis. Lancet. 343:1536-1538.

10. Greengard, J. S., X. Sun, X. Xu, J. A. Fernandez, J. H. Griffin, and B. Evatt. 1994. Activated protein $\mathrm{C}$ resistance caused by $\mathrm{Arg}^{506} \mathrm{Gln}$ mutation in factor Va. Lancet. 343:1361-1362.

11. Voorberg, J, J. Roelse, R. Koopman, H. Büller, F. Berends, J. W. ten Cate, K. Mertens, and J. A. van Mourik. 1994. Association of idiopathic venous thromboembolism with single point mutation at $\operatorname{Arg}^{506}$ of factor V. Lancet. 343:1535-1536.

12. Sun, X., B. Evatt, and J. H. Griffin. 1994. Blood coagulation factor Va abnormality associated with resistance to activated protein $C$ in venous thrombophilia. Blood. 83:3120-3125.

13. Shen, L., and B. Dahlbäck. 1994. Factor V and protein S as synergistic cofactors to activated protein $\mathrm{C}$ in degradation of factor VIIIa. J. Biol. Chem. 269:18735-18738.

14. Higuchi, R. 1989. Simple and rapid preparation of samples for PCR. In PCR Technology. H. A. Erlich, editor. Stockton Press, New York. 31-38.

15. Kaplan, E. L., and P. Meier. 1958. Nonparametric estimation from incomplete observations. J. Am. Stat. Assoc. 53:457-81.

16. Mantel, N. 1966. Evaluation of survival data and two new rank order statistics arising in its consideration. Cancer Chemother. Rep. 50:163-70.

17. Lindblad, B., P. J. Svensson, and B. Dahlbäck. 1994. Arterial and venous thromboembolism with fatal outcome in a young man with inherited resistance to activated protein C. Lancet. 343:917.

18. Rosendaal, F. R., R. M. Bertina, and P. H . Reitsma. 1994. Letter to editor Lancet. 343:1289-1290.

19. Marlar, R. A., and A. Neumann. 1990. Neonatal purpura fulminans due to homozygous protein $\mathrm{C}$ or protein $\mathrm{S}$ deficiencies. Semin. Thromb. Hemostasis. 16:299-309. 